\title{
Estudos de Arte Rupestre no Sertão Alagoano: o sítio Cosmezinho (CZ)
}

\author{
Carolina Machado Guedes (*)
}

\begin{abstract}
GUEDES, C.M. Estudos de Arte Rupestre no Sertão Alagoano: o sítio Cosmezinho
\end{abstract} (CZ). R. Museu Arq. Etn., 25: 215-230, 2015.

Resumo: No ano de 2008 a empresa Zanettini Arqueologia em interação com o IPHAN-AL iniciou um trabalho de identificação, registro e avaliação de sítios rupestres no sertão alagoano, objetivando a proposição de estratégias devotadas à fiscalização, conservação e uso público qualificado desses recursos culturais pelas populações da região. Deste trabalho originou o programa de diagnósticos de sítios rupestres no município de Pão de Açúcar, avaliando seus estados de conservação e propondo formas de uso qualificado desses locais. Além dos diagnósticos elaborados a partir das avaliações feitas sobre esses sítios, os dados coletados dentro desse programa forneceram rica documentação para pesquisas posteriores, focando principalmente no registro sistemático dos sítios e painéis rupestres. Esses sítios do sertão alagoano guardam uma notável arte, marcando e caracterizando essa área da região, pela qualidade, variedade formal, temática e técnicas aplicadas nas construções dos painéis. O objetivo desse trabalho é expor os métodos e as análises realizadas dentro desse programa, sobre o sítio de pinturas não-figurativas, o sítio Cosmezinho.

Palavras-chave: Arte rupestre; sertão alagoano; conservação; unidades não-figurativas.

\section{Introdução}

E m 2008 a Zanettini Arqueologia, em colaboração com o IPHAN-AL, realizou trabalhos de pesquisa diagnóstica e conservação de sítios rupestres nos municípios de Olho D’Água do Casado e Delmiro Gouveia, no sertão alagoano. Este trabalho teve como objetivo localizar, estudar e avaliar as condições de conservação de importantes sítios rupestres da região, para construção de um plano de uso qualificativo desses locais que articulasse sua conservação e a criação de um circuito turístico

(*) Programa de Pós-graduação em Arqueologia (doutorado), Museu de Arqueologia e Etnologia, USP. >cmguedes@gmail.com> experimental, utilizando-se para isso sobretudo de ações educativas que levassem ao uso qualitativo dos sítios (ver Zanettini 2008 para detalhamento).

Com o agenciamento do uso qualificado, a extroversão do conhecimento obtido nesses locais e o cadastramento de novos sítios na região do sertão alagoano obtidos ao final da pesquisa, foi proposta a expansão do programa através de prospecções que visassem a localização e o registro de sítios em áreas adjacentes às acima citadas.

Assim em 2009, dentro do "Programa de mapeamento, cadastro e conservação dos sítios de arte rupestre do Baixo São Francisco, Etapa 1 ", as atividades de pesquisa se concentraram na região de Pão de Açúcar, tendo sido feitos 
o levantamento, a localização e a inspeção de sítios de pinturas rupestres, e tendo-se como objetivos o registro dos sítios e a criação de propostas no que se refere à sua conservação. Os trabalhos prospectivos resultaram na localização, cadastro e registros de quatro novos sítios (Carcará I, Carcará II, Pedra do Tanque e Bom Nome II), elevando à onze o número total de sítios identificados e analisados nessa região (Zanettini, 2009).

De maneira geral, os trabalhos em campo estiveram direcionados principalmente para a avaliação dos diversos processos responsáveis pelo estado de conservação dos sítios da área, tanto os naturais (bióticos e abiótico) quanto os antropicamente produzidos.

A partir da realidade observada, foram empregados métodos de análise, segundo parâmetros desenvolvidos pela Zanettini Arqueologia (2007), que pudessem dar conta de explorar de maneira objetiva o potencial de informações advindas dos sítios, esses métodos atendiam diretamente aos objetivos do programa de pesquisa: a) Levantamento e cadastro dos sítios arqueológicos de arte rupestre no município de Pão de Açúcar/AL; b) Identificação dos fatores de degradação dos sítios e registros rupestres; c) Criação de um plano para conservação dos sítios rupestres em curto, médio e longo prazo e d) Criação de proposta para o uso público dos sítios identificados (Zanettini, 2009).

Dessa forma foi realizada uma análise qualitativa dos sítios rupestres, ou seja, foram feitas observações e avaliações sistemáticas a fim de produzir dados e captar informações que pudessem ser utilizadas em pesquisas futuras, além de promover novas visitas para a conservação dos locais estudados. A análise envolveu principalmente a observação e identificação do estado de conservação das pinturas dos registros rupestres nos sítios do município, havendo especial preocupação com seu estado de conservação e das patologias de degradação dos painéis rupestres (Zanettini, 2009).

Este artigo tem como objetivo apresentar e discutir o registro, os métodos e as análises feitas para o Sítio Cosmezinho (CZ) o qual, entre os sítios da região, possui um dos maiores conjuntos de representações rupestres.

\section{Um pouco de perspectiva teórica}

Os dispositivos rupestres são antes de tudo artefatos arqueológicos (Cavalheiro 2004: 23) e como tal, necessitam, para seu estudo, de um corpo teórico-metodológico próprio da Arqueologia. Dada a natureza fundamentalmente simbólica desse tipo de cultura material, a sua análise é potencialmente complexa, sendo fundamental sua compreensão de forma sistemática, através das análises de seus elementos formais e socioculturais.

As manifestações rupestres são interpretadas como uma forma de comunicação, de materialização de um pensamento e, sendo este o caso, os sinais rupestres carregam significados (Vialou 2009). Sem desconsiderar seu valor estético inegável, muitos pesquisadores concordam que a arte pretérita, como forma de expressão, é essencial na relação e troca de informação e conhecimento dentro de um sistema social. Dentro desse contexto, Denise Schaan (2001: 2), afirma que "(...) a arte nas sociedades iletradas é um poderoso veículo de comunicação sobre valores sociais, morais e étnicos, constituindo-se em um código socialmente aceito e compreendido".

Assim, ao trabalharmos com arte rupestre, estamos lidando com sistemas de informação, construídos através de códigos compreensíveis para aqueles que os criaram, com manifestações gráficas fundamentalmente simbólicas, socialmente organizadas, que conformam conjuntos estruturados, "em função de uma simbologia visual” (Vialou 1999: 16), conjuntos estes que foram criados e organizados com a intenção de comunicar uma ideia, um valor, uma crença, etc. Uma verdadeira transmissão gráfica de ideias compartilhadas por um grupo, registrada materialmente de maneira totalmente codificada nos suportes rochosos (Vialou 1999).

Ao tratar os dispositivos parietais como construções culturais que contêm uma forma de comunicação social consciente e simbolicamente estruturada, consideramos que as unidades gráficas, os desenhos, pinturas e gravuras de um determinado painel rupestre apresentam relações espacialmente significativas, uma vez que uma comunicação articulada exige uma organização interna para que se faça inteligível, e 
que será portadora de sentidos, compreensíveis somente por aqueles que possuem os códigos de leitura adequados (Sauvet 1993a).

Será, pois, através das análises e observações das diversas relações entre as unidades gráficas, que poderemos compreender conjuntos que foram intencionalmente construídos. Procuramos compreender as relações que foram estabelecidas e codificadas pelos autores pretéritos, e essa leitura se torna assim de grande relevância para a pesquisa.

Se não podemos saber o que os registros rupestres significam, sabemos ao menos que eles significaram algo, disso decorre que a pesquisa dos painéis rupestres, na perspectiva teórica que este trabalho assume, deve levar à compreensão do fenômeno propriamente dito e não à tentativa de compreensão de seu significado. A perspectiva do trabalho no sítio Cosmezinho foi justamente a de tentar compreender o comportamento sociocultural que criou as manifestações rupestres presentes no sítio, se o significado está para sempre perdido, a materialização desses processos ficou gravada nos suportes rupestres, e neles podemos identificar as escolhas, observar as relações internas responsáveis por construir os sentidos, as estruturas de organização dos discursos, de pensamentos estabelecidos, de comportamentos praticados.

Dessa forma, como se tratam de painéis portadores de funções simbólicas e de comunicação social, organizados de maneira arbitrária e consciente, ao observar analiticamente um painel rupestre, o arqueólogo pode perceber uma série das regras de composição dos elementos simbólicos (Vialou, 1998: 274).

A descrição dos sinais rupestres se reveste de grande importância para que essa leitura seja possível, sendo ela o instrumento que nos permite perceber suas recorrências, suas variações e suas singularidades. Dentro desse âmbito, ao trabalhar com os sinais rupestres, lidamos com um universo totalmente abstrato, cuja chave de decodificação nos escapa a priori, mas ao qual nos acostumados a acrescentar significados, construindo relações mentais a partir daquilo que conhecemos, ou seja, interpretando algumas formas através das analogias que apresentam com às formas de nossa própria cultura material. Assim, é frequente que sejam identificados sinais designados como 'tipo pente', ou 'sol', ou 'grelha', etc. (Sauvet 1993b).

No entanto, para que a classificação tipológica das unidades gráficas não acabe por contaminar o trabalho analítico dos painéis, sua leitura, com atribuição de significados espúrios essa classificação tipológica deve ser isenta no seu tratamento semântico, quer dizer, vazia de significado.

\section{Métodos}

De maneira geral, em um primeiro momento, procedeu-se a classificação básica dos registros rupestres. Essa classificação é composta por três categorias que incluem basicamente a variedade dos registros rupestres existentes por todo o globo: a) não-figurativos; b) figurativos; e c) indeterminados (Guedes 2014).

Os registros não-figurativos são descritos também como abstratos, grafismos puros, ou geométricos, e estiveram presentes em maior quantidade nos sítios pesquisados na região do município de Pão de Açúcar. São compostos por uma grande variabilidade de representações geométricas, desde as mais elementares até composições muito complexas e se constituem no que em geral chamamos de sinais.

A ideia geral de sinal pode em muitos casos, dependendo tanto do local quanto da metodologia empregada, se desdobrar em outros conceitos, como o de signos e símbolos. Conceitualmente, signos, sinais e símbolos diferem entre si, mas no contexto da arte rupestre integram o conjunto, são partes isoladas, que adquirem sentido quando reunidos (Sauvet 1993b). A identificação dessas partes, e as relações entre elas são fundamentais porque apontam para as relações existentes entre os elementos pictográficos rupestres dentro de um determinado conjunto, auxiliando na tarefa de interpretar a coerência interna dos registros.

Os registros figurativos são aqueles que apresentam formas que podem ser reconhecidas e atribuíveis a três categorias; a) humanas; b) animais; e c) plantas. Os registros figurativos podem representar estas categorias por sua composição 
completa, por sugestões gráficas e inferenciais, como no caso de mãos e pegadas, ou ainda através de traços compondo perfis (Sauvet 1993b).

Por fim os registros indeterminados são aqueles que não podem ser atribuídos a nenhuma das categorias anteriores, seja pelo seu estado de conservação, seja pela sua própria formação gráfica.

Em função principalmente do tempo disponível, a técnica do decalque digital foi a principal ferramenta de trabalho para o registro em campo. Nessa técnica de decalque digital, aplicada em campo por Antônio Cavalheiro os registros devem ser feitos de forma rigorosa in loco, através de fotografias em meio digital das pinturas com escalas métricas, sendo realizada uma subdivisão prévia do painel em que se encontram as pinturas e registros rupestres. Faz-se então em computador, com softwares especializados, a segregação do registro pela captura das cores, podendo ser ampliadas a seu tamanho natural bem como serem manipuladas facilmente (Zanettini, 2009).

Devido às características naturais da conformação do sítio Cosmezinho e também da complexidade gráfica dos painéis o registro em campo foi feito de forma a tratar primeiro os painéis mais simples, situados nas paredes, e depois os painéis mais complexos situados sobre o teto. Por último foi feito o registro de um painel isolado, que apesar de integrar o conjunto do sítio não está localizado no suporte dado pelo matacão central.

\section{A Região de Pão de Açúcar e o sítio rupestre Cosmezinho}

O município de Pão de Açúcar localiza-se no centro-oeste do Estado de Alagoas, sendo seu limite meridional dado pelo rio São Francisco e o estado de Sergipe (fig. 1). Ele está inserido na mesorregião do sertão alagoano e na microrregião de Santana do Ipanema (Zanettini, 2009). A região está inserida na caatinga, composta por caatinga hiperxerófila com trechos de floresta caducifólia e apresenta uma rede hidrográfica que inclui córregos e riachos intermitentes, que integram a bacia do rio São Francisco, destacando-se entre eles o Rio Capiá, o Riacho das Cacimbas, o Riacho do Carcará e o Riacho Grande (Zanettini 2009: 7). No que se trata de seus aspectos geomorfológicos, a região é caracterizada pela

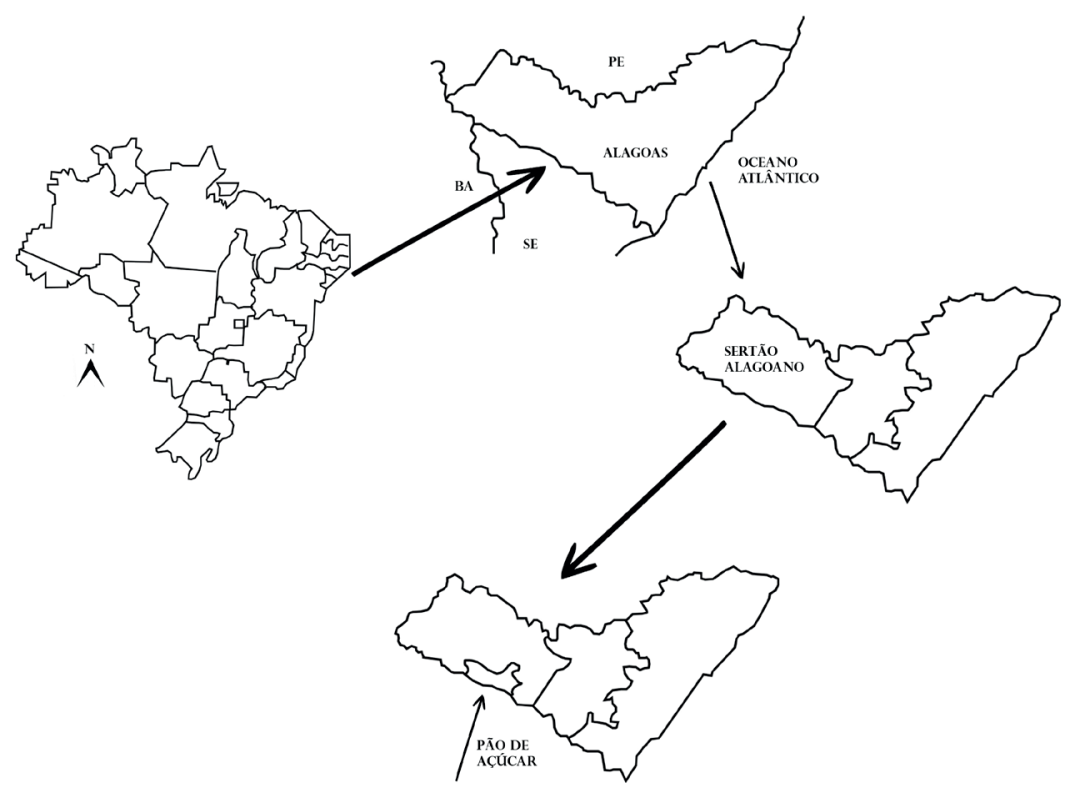

Fig.1. Área de estudo 
“depressão sertaneja (pediplano do Baixo São Francisco), com suas superfícies de pediplanação e inselbergues, e pela bacia do Jatobá" (op. cit.).

A área da pesquisa concentra vários sítios com dispositivos rupestres e no total foram estudados os sítios: Bom Nome I, Bom Nome II, Bom Nome III, Bom Nome IV, Carcará I, Carcará II, Cosmezinho, Cuidado, Pedra do Tanque, Morro do Lampião e Ilha dos Cavalos.

Todos os onze sítios se destacam pela temática dos dispositivos rupestres, compostos principalmente por unidades não-figurativas, e pela variabilidade no que se refere a sua organização parietal. A originalidade de cada sítio se firmou como um traço marcante nessa região.

O sítio rupestre Cosmezinho (CZ) é o maior da região e foi identificado pela equipe da Universidade Federal de Alagoas, sob a coordenação do pelo Prof. Dr. Scott Joseph Allen (apud Gontijo 2006). Localiza-se à margem esquerda do riacho Olho d"Aguinha, que aflui ao córrego Carcará, tendo ambos caráter sazonal, sendo os terrenos do redor marcados por interflúvios bem definidos e ondulações (Zanettini 2009: 53).

O sítio é formado por um grande matacão circular sobreposto a outros blocos menores de granito, lembrando um grande dólmen (ainda que natural). Sua topografia original faz com que cada área de cada painel seja diferente de todas as outras no seu entorno e isso significa que cada painel tem uma construção original não somente no tocante ao conjunto específico da temática selecionada, mas também em relação ao seu próprio nicho.

Para conhecer o sítio como um todo é necessário percorrer o seu contorno, perfazendo um total de 18,00 m de diâmetro aproximadamente e cada perfil apresenta uma natureza única. Via de regra, as fachadas apresentam-se homogêneas, e nelas em muitos locais os contornos naturais do suporte foram utilizados para enquadrar ou associar as distintas unidades gráficas. Estão presentes 7 áreas distintas, que integram um mesmo grande matacão. As áreas abrigadas são em sua maioria de altura reduzida, exigindo que alguns painéis sejam observados somete em posições abaixadas ou deitadas. De maneira geral há pouca área abrigada em todo o seu redor (fig.2).

Ainda que sua característica natural única desperte a curiosidade, sua localização em baixa vertente evita que seja possível uma observação ao longe. Essa disposição na paisagem, a proteção
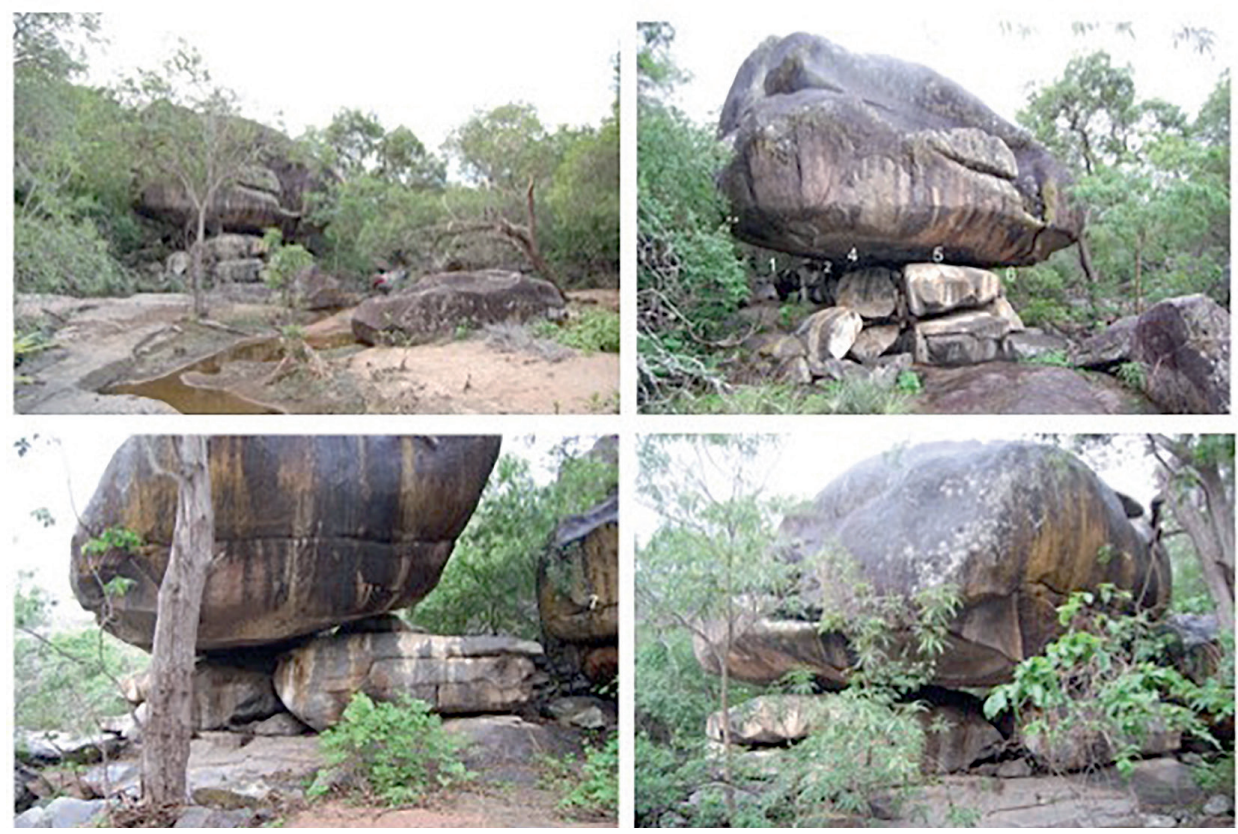

Fig.2. Fotografias das diversas faces do matacão onde os painéis estão pintados. Foto: A. Cavalheiro. 
conferida pela vegetação circundante, a proximidade a um pequeno córrego, apontam a importância do local discreto, sendo características que, se não tornam o acesso ao sítio propriamente difícil, evitam que ele seja evidente na paisagem.

Apesar de não haverem datações nem escavações e prospecções intensivas, uma grande quantidade de material lítico foi observado no sítio, em superfície, no entorno da área em que as pinturas se localizam, o que sugere que tenha sido utilizado (ou mesmo ocupado) ao longo de um espaço de tempo razoavelmente longo.

\section{A arte rupestre do sítio Cosmezinho: Uma discussão analítica}

Do ponto de vista da arte rupestre, o sítio Cosmezinho é um dos maiores e mais complexos da região, e nele foram identificadas 107 unidades gráficas classificadas em 54 tipos distintos, incluindo unidades gráficas classificadas como não-figurativas, como figurativas e como indeterminadas (tabela 1, fig. 3).

Todos os registros rupestres presentes no sítio são pinturas ou desenhos em crayon e ocupam a quase totalidade da área, incluindo nichos abobadados no teto. Foram identificados 7 painéis rupestres no sítio, sendo seis no matacão principal e um (o sétimo), mais afastado deste, pintado em outro suporte. A disposição do matacão criou condições de conservação particularmente boas no sítio, o que permitiu uma preservação dos painéis, suas cores permanecem fortes e os contrastes visíveis.

A paleta de cores nesse sítio é bem diversificada, com uso de cinco diferentes cores, além da variação da tonalidade do vermelho. $\mathrm{O}$ amarelo e o laranja se destacam na criação de unidades policromas, o pigmento branco, com consistência um pouco pastosa e o preto também foram utilizados.

As unidades gráficas não figurativas predominam no sítio, respondendo por 98 registros do total documentado e por 45 tipos identificados, variando de padrões simples a padrões muito complexos e elaborados. As formas circulares (tipos 4 ao 16), as losangulares (tipos 24 e 25) e as triangulares (tipos 22 e 23) são as mais comuns e apresentam grande variedade de declinações (tabela 1, fig. 3). Chama a atenção, principalmente, a grande variedade de preenchimentos das formas circulares, o que, devido ao rigor dos critérios de classificação, levou ao reconhecimento de 14 tipos circulares distintos (tabela 1, fig. 3). De fato, se o rigor dos critérios classificatórios das formas circulares for reduzido o número total de tipos reconhecidos é reduzido para 40 .

Os registros figurativos ocorreram no sítio em número bastante reduzido, tendo sido documentadas 9 unidades, classificadas em 4 diferentes tipos (tipos 46 ao 49). Dentre os registros figurativos animais, no tipo 47 foram incluídos 5 unidades gráficas, todas incompletas. Uma delas, particularmente, apresenta duas patas tridígitas com pernas esticadas em direção à parte anterior do corpo, a cabeça por sua vez, está apenas sugerida num pequeno vértice. As demais unidades são extremamente esquemáticas e seus aspectos de animais podem ser apenas inferidos. $\mathrm{O}$ tipo 48, também figurativo, é uma pegada com 4 dedos. Dentre as figuras humanas, extremamente esquemáticas, foram identificados apenas 2 unidades gráficas, uma delas apresenta-se incompleta (tipo 49), e nela podemos perceber apenas a parte inferior do corpo, as pernas e os pés triangulares. O segundo registro, assemelha-se a um humano deitado extremamente estilizado (tabela 1, fig. 3).

$\mathrm{Na}$ totalidade do sítio foram documentados 5 unidades gráficas que classificamos como indefinidas, e que perfazem 5 tipos distintos (tipos 50 ao 54). Trata-se de figuras bastante complexas que não puderam ser decompostas em unidades menores, nem representam formas figurativas inequívocas. São associações de quadrangulares, linhas, pontos, ondulações, ziguezagues e vértices. Também o tipo 46, apesar de nos sugerir uma unidade figurativa um utensílio, acabou sendo classificado como indefinido (tabela 1, fig. 3).

Considerando-se os painéis rupestres, aqui entendidos como os conjuntos de representações rupestres definidos através de delimitações naturais (p. ex. fendas, relevos do próprio suporte) ou artificiais (p. ex. relação espacial entre os grupos de conjuntos gráficos) (Vialou 1999), eles são, em sua maioria, compostos de elementos gráficos não-figurativos, cujos padrões variam das formas 


\begin{tabular}{|c|c|c|c|c|c|}
\hline Tipo & Descrição & $\begin{array}{l}\text { Quantidade } \\
\text { de grafismos }\end{array}$ & Tipo & Descrição & $\begin{array}{l}\text { Quantidade } \\
\text { de grafismos }\end{array}$ \\
\hline 1 & Pontos seriados & 1 & 28 & $\begin{array}{c}\text { Linhas paralelas verticais com } \\
\text { extremidades alongadas e sinuosa } \\
\text { e traços (2) externos }\end{array}$ & 1 \\
\hline 2 & Ponto raiado & 1 & 29 & $\begin{array}{c}\text { Agrupamento de pequenas } \\
\text { linhas }\end{array}$ & 1 \\
\hline 3 & Circular raiado & 1 & 30 & $\begin{array}{l}\text { Associação de linhas horizontais } \\
\text { irregulares paralelas sobre uma } \\
\text { perpendicular e um círculo }\end{array}$ & 1 \\
\hline 4 & Circular simples & 5 & 31 & Vértices empilhados em 3 faixas & 1 \\
\hline 5 & Circular concêntrico (1) & 8 & 32 & Ziguezagues & 4 \\
\hline 6 & Circular concêntrico (2) & 4 & 33 & Losangular associados & 2 \\
\hline 7 & Circular concêntrico (3) & 4 & 34 & $\begin{array}{c}\text { Associação de losangos ligados } \\
\text { pelo vértice }\end{array}$ & 2 \\
\hline 8 & $\begin{array}{l}\text { Circular concêntrico (4) com } \\
\text { raiados externos }\end{array}$ & 1 & 35 & $\begin{array}{l}\text { Associação de triângulos ligados } \\
\text { pelo vértice e vértice/base }\end{array}$ & 1 \\
\hline 9 & $\begin{array}{l}\text { Circular concêntrico ( } 3 \text { ) com } \\
\text { triangulares externos (raiados) }\end{array}$ & 1 & 36 & Triângulos associados & 4 \\
\hline 10 & $\begin{array}{c}\text { Circular concêntrico (2) com } \\
\text { linhas internas convergentes ao } \\
\text { círculo central }\end{array}$ & 1 & 37 & $\begin{array}{c}\text { Associação de triângulos ligados } \\
\text { pelo vértice em faixa }\end{array}$ & 1 \\
\hline 11 & $\begin{array}{l}\text { Circular com semi-círculos } \\
\text { externos e linhas divergentes } \\
\text { do círculo central }\end{array}$ & 1 & 38 & Quadrangular simples & 3 \\
\hline 12 & $\begin{array}{l}\text { Circular com duas linhas } \\
\text { internas perpendiculares }\end{array}$ & 1 & 39 & Quadrangular concêntrico & 1 \\
\hline 13 & $\begin{array}{l}\text { Circular com linhas internas } \\
\text { convergentes ao círculo central }\end{array}$ & 5 & 40 & $\begin{array}{l}\text { Quadrangular com preenchimen- } \\
\text { to em xadrez }\end{array}$ & 1 \\
\hline 14 & $\begin{array}{l}\text { Circular com linhas convergen- } \\
\text { tes à parte mediana interna }\end{array}$ & 1 & 41 & $\begin{array}{c}\text { Quadrangular com preenchimen- } \\
\text { to regular de pontos e pequeno } \\
\text { quadrangular }\end{array}$ & 1 \\
\hline 15 & $\begin{array}{l}\text { Circular com } 3 \text { linhas irregula- } \\
\text { res paralelas cortadas por uma } \\
\text { perpendicular }\end{array}$ & 1 & 42 & $\begin{array}{l}\text { Quadrangular aberto com linhas } \\
\text { internas }\end{array}$ & 2 \\
\hline 16 & $\begin{array}{l}\text { Circulares formadas e preen- } \\
\text { chidas pela associação de } \\
\text { triangulares }\end{array}$ & 3 & 43 & $\begin{array}{l}\text { Ovalar irregular com preenchi- } \\
\text { mento de linhas paralelas }\end{array}$ & 1 \\
\hline 17 & $\begin{array}{c}\text { Circulares concêntricas associa- } \\
\text { das à quadrangulares } \\
\text { (1 com arestas arredondadas) }\end{array}$ & 2 & 44 & Ovalar irregular concêntrico & 2 \\
\hline 18 & $\begin{array}{l}\text { Semi-circulares com preenchi- } \\
\text { mento interno }\end{array}$ & 2 & 45 & Forma de $\mathrm{X}$ vazado & 1 \\
\hline 19 & $\begin{array}{l}\text { Semi-oval com tracejados } \\
\text { paralelos internos }\end{array}$ & 1 & 46 & Figurativo (utensílio?) & 1 \\
\hline
\end{tabular}




\begin{tabular}{|c|c|c|c|c|c|}
\hline Tipo & Descrição & \multirow{2}{*}{$\begin{array}{c}\begin{array}{c}\text { Quantidade } \\
\text { de grafismos }\end{array} \\
\text { identificados }\end{array}$} & \multicolumn{2}{|r|}{ Descrição } & \multirow{2}{*}{ 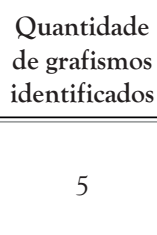 } \\
\hline 20 & $\begin{array}{l}\text { Ovalar com uma extremidade } \\
\text { em fuso preenchida interna- } \\
\text { mente }\end{array}$ & & 47 & Figurativo (animais incompletos) & \\
\hline 21 & $\begin{array}{l}\text { Forma de fuso com uma linha } \\
\text { interna }\end{array}$ & 2 & 48 & Figurativo (pegada) & 1 \\
\hline 22 & Triangular com linhas internas & 2 & 49 & $\begin{array}{l}\text { Figurativo (humano estilizado e } \\
\text { incompleto) }\end{array}$ & 2 \\
\hline 23 & $\begin{array}{l}\text { Triangular irregular com preen- } \\
\text { chimento interno }\end{array}$ & 1 & 50 & Indefinido & 2 \\
\hline 24 & Losangular simples & 1 & 51 & Indefinido & 1 \\
\hline 25 & Losangular concêntrico & 1 & 52 & Indefinido & 1 \\
\hline 26 & Linhas paralelas & 5 & 53 & Indefinido & 2 \\
\hline 27 & Linhas paralelas verticais & 4 & 54 & Indefinido & 2 \\
\hline & & & & Total & 107 \\
\hline
\end{tabular}

Tabela 1: Descrição dos tipos utilizados na classificação

simples até as mais complexas e elaboradas. A variação na complexidade está presente também na composição dos painéis em seu conjunto e pode ainda ser constatada em relação à utilização das cores, que ocorrem em maior número nos painéis mais complexos. Além disso, existe uma clara distinção entre os 7 painéis no tocante ao seu tamanho, notadamente os painéis 4, 5 e 6, todos eles localizados sobre o teto do suporte rochoso e maiores que os demais.

O painel 1 mede aproximadamente $0,30 \mathrm{~m}$ x $0,27 \mathrm{~m}$ e é composto de 5 unidades gráficas, todas elas distintas entre si. Se por um lado 3 delas encontram-se incompletas (devido às alterações do suporte), as duas unidades restantes apresentam características formais de grande interesse, visto que podem ser considerados como figurativos. São formas que sugerem instrumentos, utensílios ou mesmo adereços (fig. 4 e fig. 5).

O painel 2 ocupa um espaço de aproximadamente $0,45 \mathrm{~m} \times 0,80 \mathrm{~m}$ e apresenta apenas 3 unidades gráficas, todas em vermelho. Duas unidades gráficas desse painel apresentam entre si uma diferença formal, porém não de composição. Trata-se de um quadrado preenchido por outro quadrado menor em seu interior, e de um círculo concêntrico, ou seja, com outro círculo menor em seu interior. A terceira unidade é um empilhamento de vértices, ou seja, figuras lineares compostas em forma de "V", formando uma longa faixa (fig. 6).

O painel 3 apresenta dimensões bastante maiores que os painéis 1 e 2 e mede 1,80 × 2,10 $\mathrm{m}$. Ele é formado por 9 unidades gráficas e apresenta duas diferenças marcantes em relação aos anteriores: a utilização de um pigmento branco e uma superposição de pinturas. Ainda que alguns sejam apenas vestigiais, ou mesmo incompletos, os sinais (ou seja, formas não-figurativas) ainda dominam a temática, sendo a forma circular a mais utilizada (fig. 7).

O painel 4 tem a dimensão de $3,00 \mathrm{x}$ $2,50 \mathrm{~m}$, e é um dos mais complexos de todo o dispositivo. Novamente as pinturas não-figurativas predominam e apenas 3 unidades podem ser compreendidas como figurativos, ainda que com ressalvas, tratando-se provavelmente de uma pegada animal, um humano incompleto e um animal também incompleto (tipos 48 e 49, fig. 3). As demais, totalizando 40 unidades gráficas, apresentam uma composição única e, em sua maioria, são declinações do círculo, uma forma 

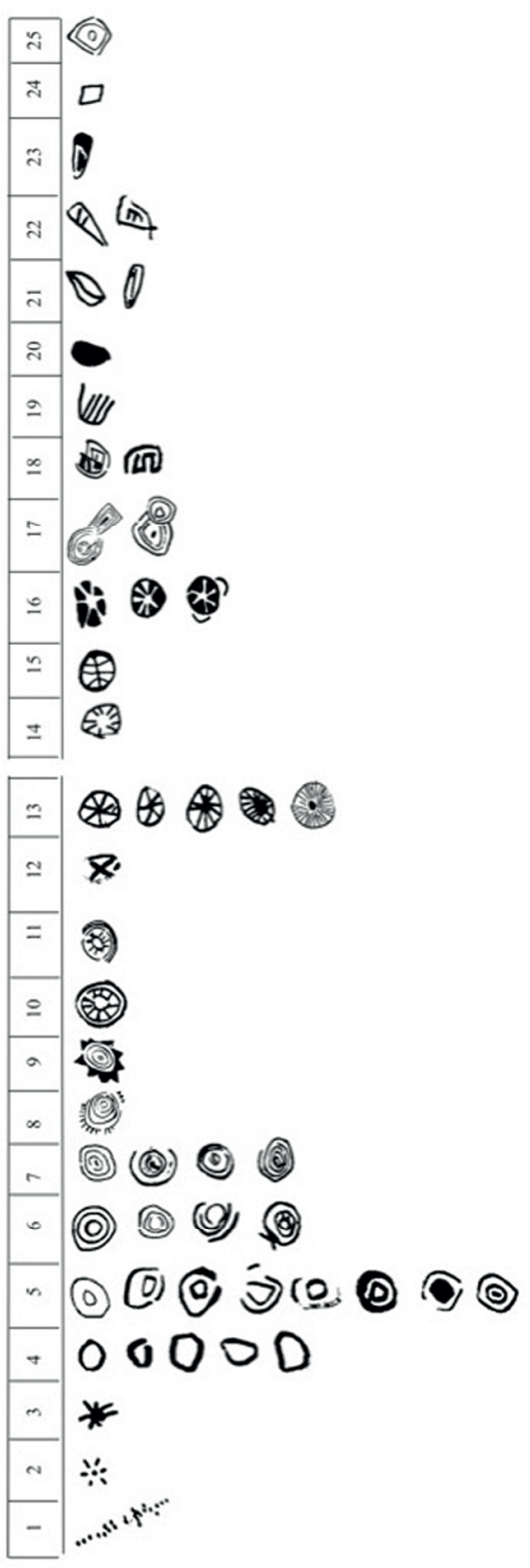
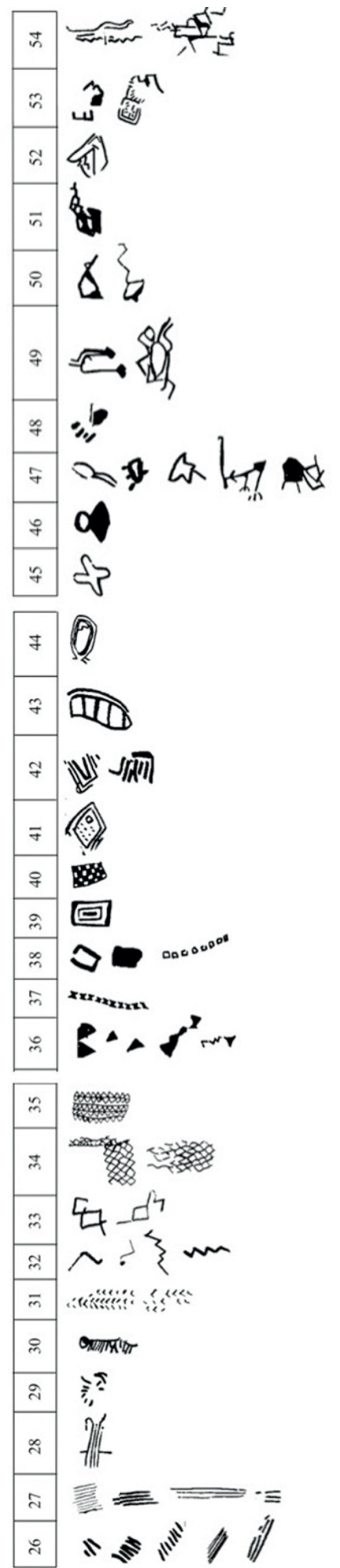

Fig.3. Unidades gráficas observadas no sítio classificadas segundo os tipos 

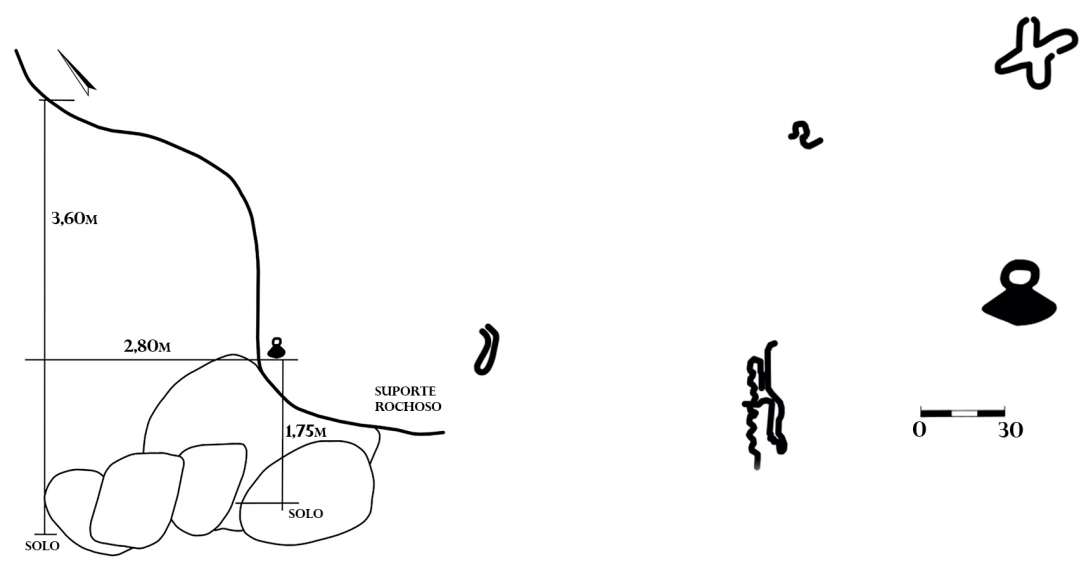

Fig.4. Perfil e organização do painel 1


Fig.5. Detalhes das pinturas do painel 1 - Fotos: A. Cavalheiro

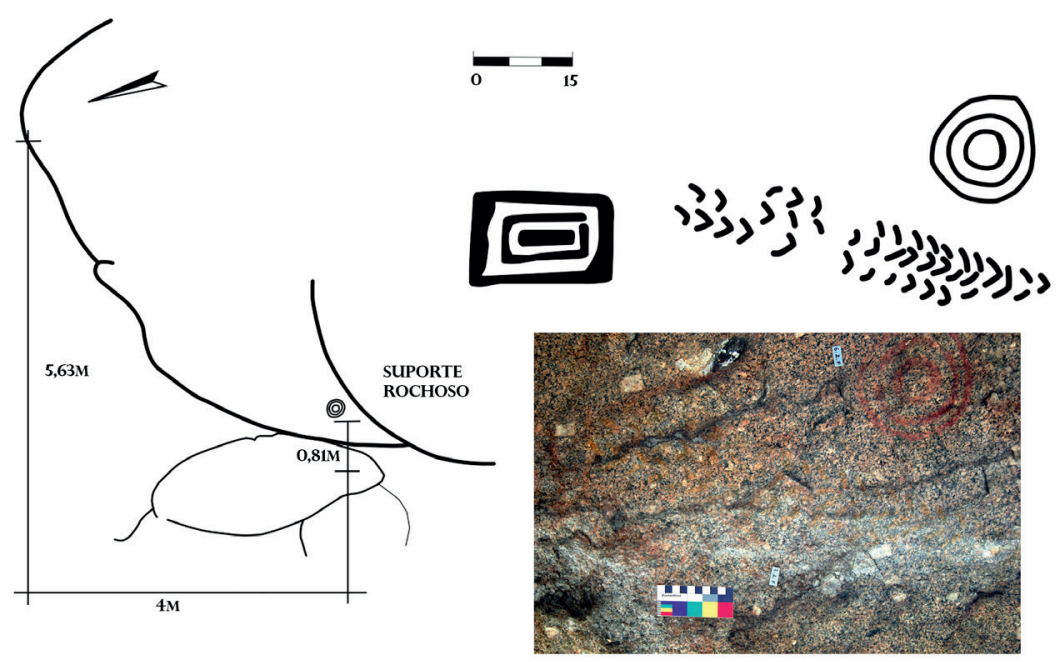

Fig.6. Perfil, organização e detalhe das pinturas do painel 2 - Foto: A. Cavalheiro 


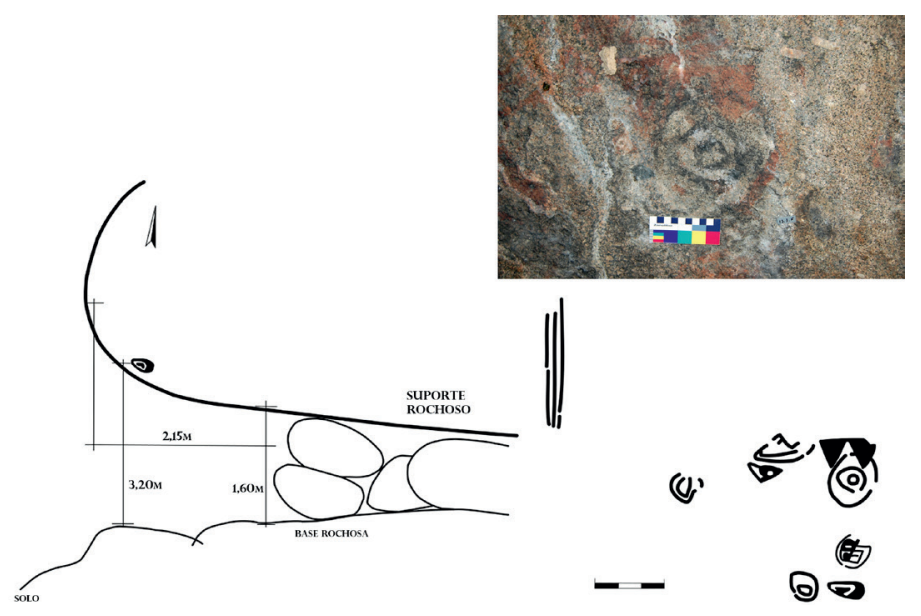

Fig.7. Perfil, organização e detalhe das pinturas do painel 3 - Foto: A. Cavalheiro

simples que no caso desse painel se desdobra em unidades muito bem estruturadas. Trata-se de círculos concêntricos, concêntricos com traços internos, concêntricos com superposição, concêntricos bicromos com união de formas quadrangulares preenchidas, e concêntricos cercados por triângulos internamente preenchidos. Além dessas formas circulares, há conjuntos de traços, pequenos quadrados enfileirados, retângulos abertos com preenchimento de traços. A paleta de cores inclui o vermelho, o laranja e o preto e é fundamental na construção simbólica desse painel que apresenta unidades em bicromia (fig. 8 e fig. 9).

O painel 5 mede 3,50 × 2,00 m e também apresenta grande complexidade, com a paleta de cores seguindo as mesmas características do painel 4. Ao todo, esse painel apresenta 29 unidades gráficas, cujos tamanhos variam entre $0,60 \times 0,60 \mathrm{~m}$ (a maior) e aproximadamente 0,09 x 0,08 m (a menor). Neste painel também se registra uma unidade tricolor, ocorrência única em todo o dispositivo.

A declinação do formato circular também foi amplamente utilizada na composição das formas, no entanto as combinações apresentam várias diferenças em relação ao painel 4 estando pressentes círculos concêntricos com raiados externos, círculos com tracejados internos, círculos com triângulos internos, sendo que em 6 unidades são policrômicas (incluindo a tricomia em um caso), um formato quadrangular com um padrão de "xadrez" e tracejados



Fig.8. Perfil e organização do painel 4 

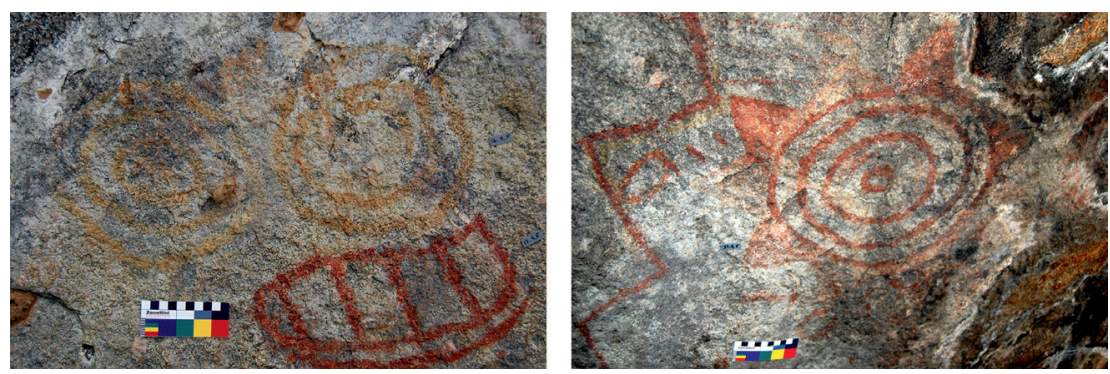

Fig.9. Detalhes das pinturas do painel 4 - Fotos: A. Cavalheiro

em paralelo relacionados às figuras circulares. Duas unidades podem ser identificadas como figurativas porém são extremamente esquematizadas, o que dificulta a sua avaliação exata (fig. 10 e fig. 11).

O painel 6 tem um tamanho de 2,50 x 2,00 $\mathrm{m}$, nele foram identificadas 32 unidades gráficas além de aspectos de composição completamente originais em relação aos demais. Ainda que a forma circular esteja presente, o traço é o principal meio de composição e articulação das unidades gráficas.

No geral o painel é dividido em duas partes. A primeira está localizada na parte mais inferior do suporte e apresenta composições mais isoladas entre si. Ainda que as 8 unidades gráficas identificadas apresentem-se articuladas no que se refere sua organização espacial, elas apresentam distâncias entre si que sugere, aparenta, um isolamento entre elas. A única exceção é uma composição que agrega duas pinturas circulares, uma sucessão de pontilhados e um dentilhado. Nesse conjunto, apontamos também para a presença de círculos concêntricos e triângulosduplos divergentes, enfileirados, formando uma grande faixa. A segunda parte desse painel se destaca pela relação intrínseca das unidades gráficas, dificultando a separação delas para uma interpretação analítica das diferentes partes. Outra característica é a presença de uma pintura figurativa (tipo 47, fig. 3 ),
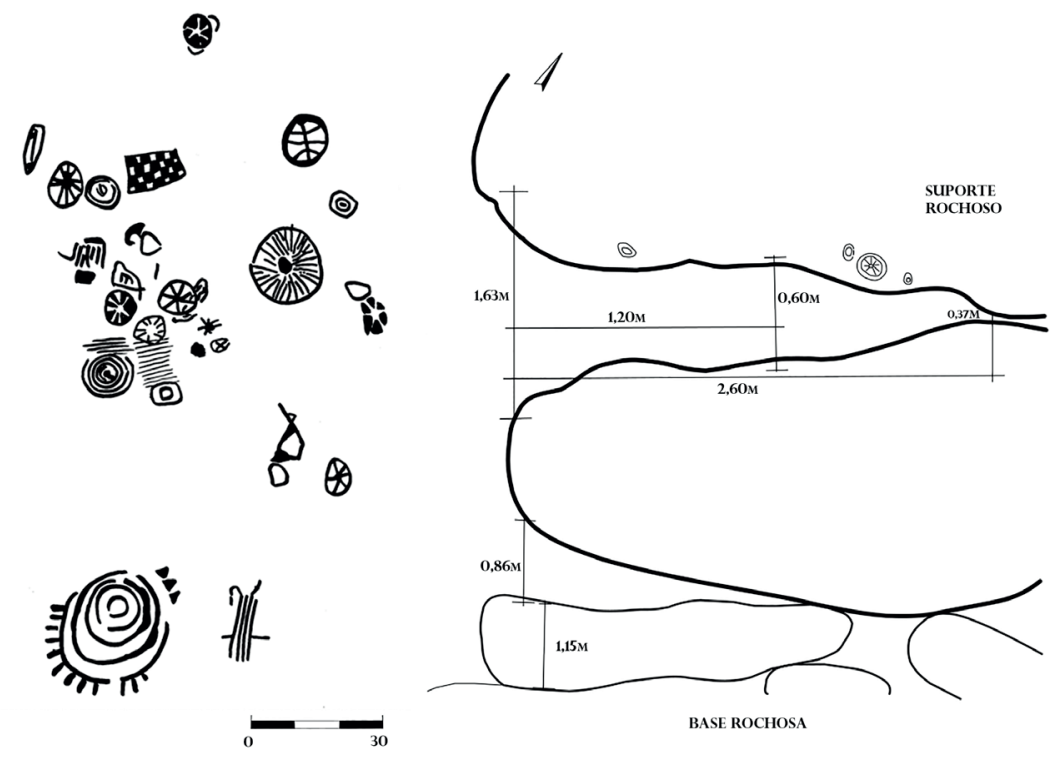

Fig.10. Perfil e organização do painel 5 

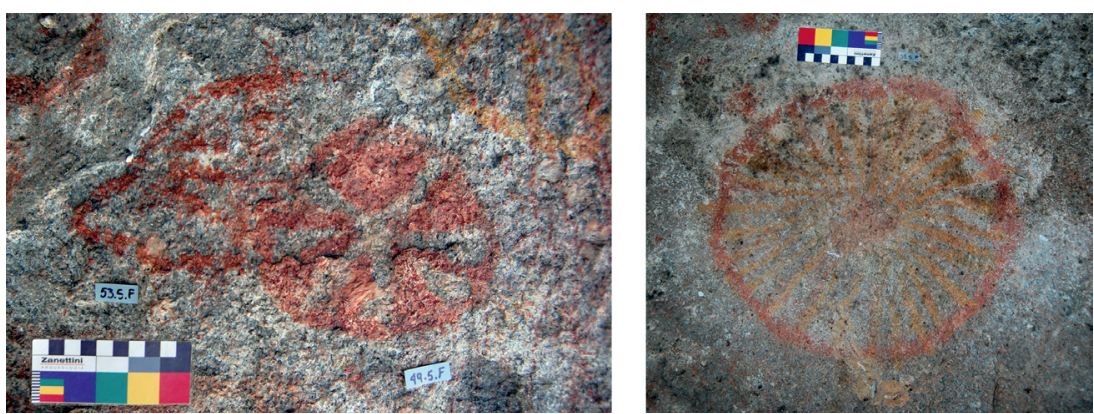

Fig.11. Detalhes das pinturas do painel 5 - Fotos: A. Cavalheiro

muito esquematizada, na qual podemos perceber um corpo alongado e tridígitos, lembrando um lagarto. Outro registro figurativo, e igualmente esquematizado, está incompleto mas ainda pode-se perceber duas pernas com pés triangulares (tipo 49, fig. 3). As demais são composições nãofigurativas, porém entram na classificação das não-identificadas. Além de formatos losangulares, ziguezagues, quadrados com preenchimentos pontilhados e quadrados com preenchimento de tracejados (fig. 12 e fig. 13).

$O$ painel 7 mede $1,45 \times 0,65 \mathrm{~m}$ e as unidades gráficas que o compõe estão a aproximadamente $1,80 \mathrm{~m}$ do solo. Apresenta características que o diferenciam dos demais, notadamente quanto à temática das unidades gráficas e quanto à localização espacial.

No que se refere à localização este painel foi pintado em uma parede de um suporte rochoso distinto dos demais e não se encontra sobre o grande matacão principal do sítio. Do ponto de vista da composição gráfica apresenta apenas 3 unidades não-figurativas, as quais, no entanto, são muito distintas das demais unidades gráficas presentes no sítios, são muito bem elaboradas com entrelaçamento de ziguezagues e triângulos, formando um padrão decorativo, como rede (fig. 14).

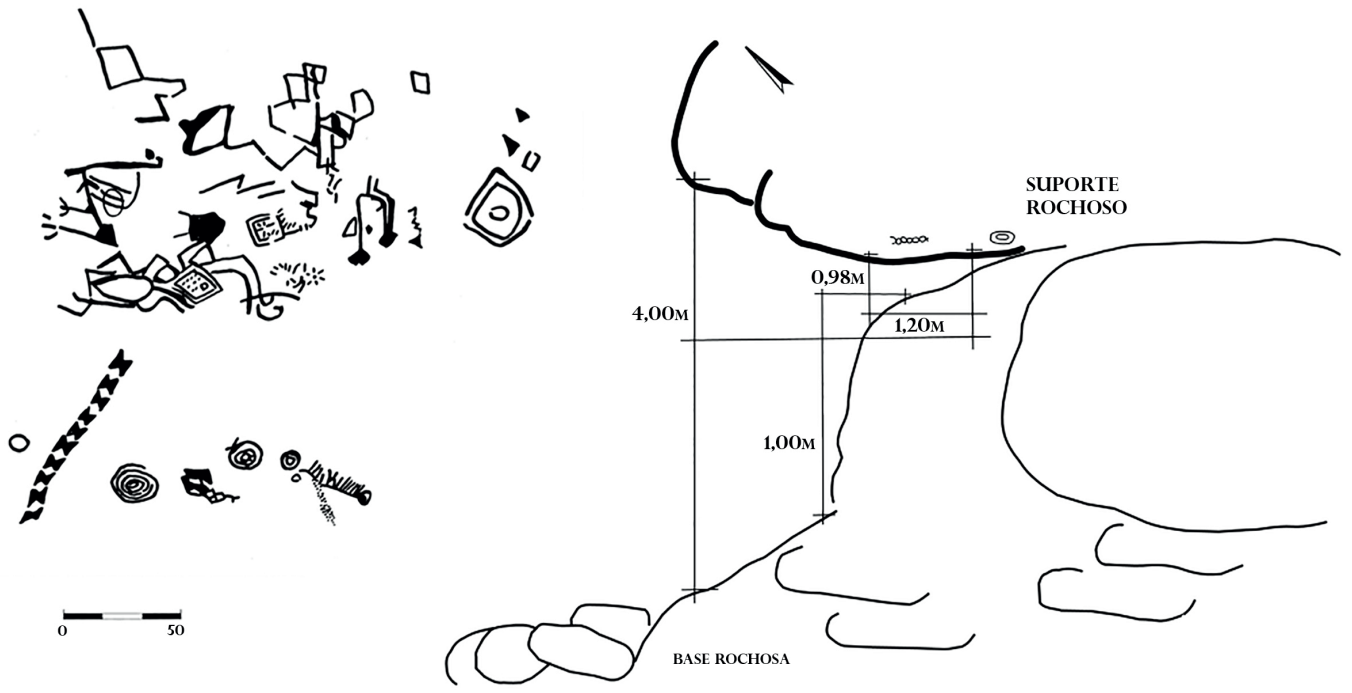

Fig.12. Perfil e organização do painel 6 

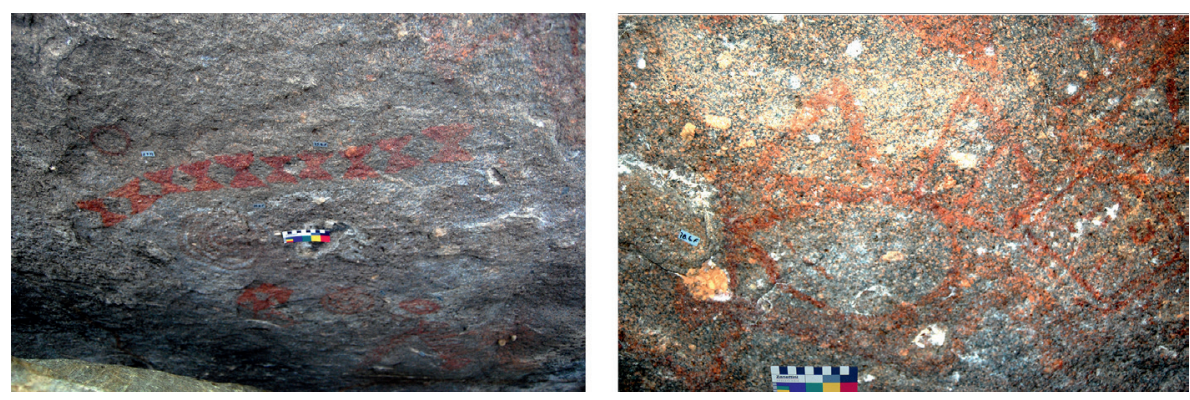

Fig.13. Detalhes das pinturas do painel 6 - Fotos: A. Cavalheiro
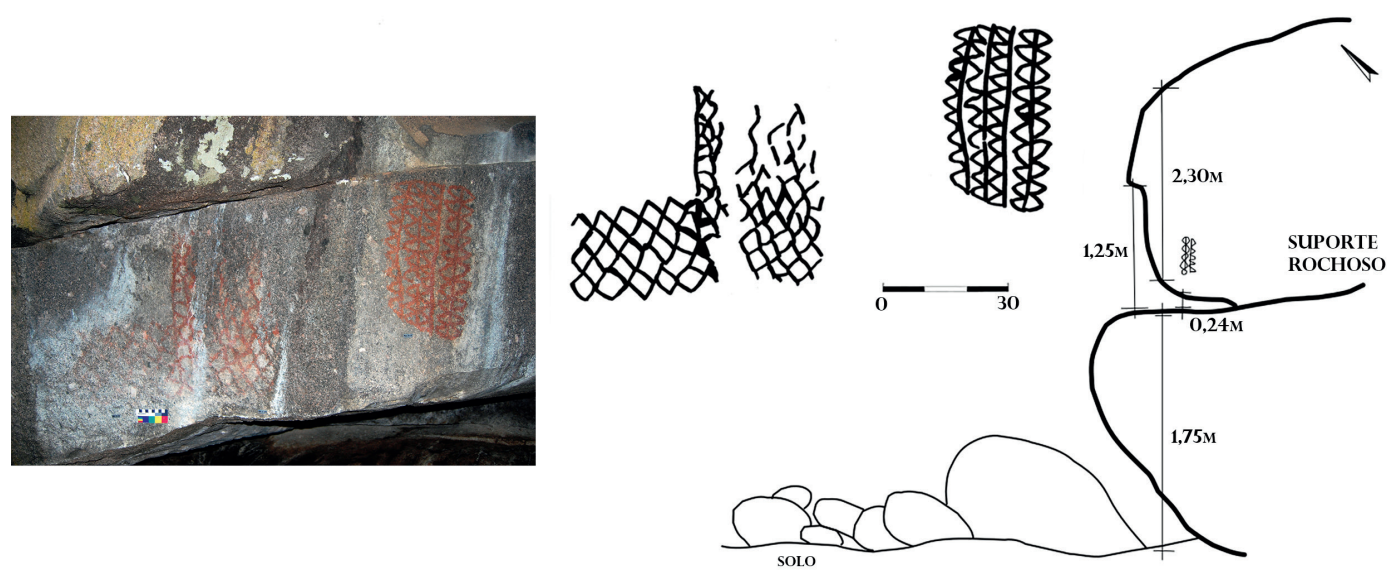

Fig.14. Perfil, organização e fotografia do painel 7. Foto: A. Cavalheiro

\section{Considerações finais}

A categorização analítica empregada nesse estudo nos permite fazer apontamentos interessantes. É notável que um universo formal extremamente rico e variado, como o expresso no registro rupestre do sítio Cosmezinho, seja, ao mesmo tempo, produto de ações de reinterpretação das mesmas formas, particularmente das formas circulares (tipos 3 ao 16, fig. 3) e das losangulares e triangulares (tipos 33 ao 37, fig 3).

Como já dissemos, essa declinação importante de um mesmo tipo se torna ainda mais notável quando consideramos uma categoria circular mais geral, uma vez que as inúmeras variantes dessa forma demonstra, com muita pertinência, que dentro de uma escolha formal básica a variedade de expressões se pode tornar extremamente complexa.
As formas circulares declinam-se desde as mais simples sem nenhum preenchimento (tipo 4, fig. 3), passando por preenchimentos concêntricos com vários níveis (com a presença de 1 até 4 círculos concêntricos), concêntricos raiados (tipos 8 e 9, fig. 3), circulares com linhas internas convergentes (tipos 10 a 13 , fig. 3), paralelas (tipo 15, fig. 3), preenchidas ou formadas por triangulares (tipo 16, fig. 3), e associadas com quadrangulares (tipo 17 , fig. 3). Esse fato é interessante no que tange a construção simbólica do dispositivo levando em consideração as escolhas e opções temáticas tomadas na sua concepção.

O segundo grupo tipológico que apresenta declinações importantes, os losangulares e triangulares, compõem padrões estruturados com as formas entrelaçadas, ou rendada (tipos 34 e 35, fig. 3). 
No conjunto do dispositivo também está presente uma pequena declinação das unidades quadrangulares, nas quais as composições dos tipos varia pelos seus preenchimentos. Pontos seriados e linhas paralelas tanto na horizontal quanto na vertical completam o dispositivo.

Analisando sistematicamente o sítio, e pensando sobre a forma do discurso deixado, se percebe que os sinais bem como cada registro que compõe o todo do dispositivo rupestre, foram selecionados cuidadosamente para construir um tipo específico de mensagem da mesma forma como cada palavra é escolhida para construir uma frase. Ao dizer isso não estamos propondo que os dispositivos rupestres se portem como uma espécie de pré-escrita, apenas chamamos a atenção para a importância semântica de cada sinal na construção de sentido do sítio como um todo, integrando um discurso simbólico articulado. O que podemos apreender é a escolha formal: o que, dentre a quase infinita possibilidade de formas e associações que os pré -históricos poderiam ter selecionado, inventado, organizado, foram as escolhidas, possuindo funções específicas para registrar e informar o que era pretendido.

Igualmente interessante é a utilização da topografia natural do suporte pelos grupos que produziram o registro rupestre do sítio Cosmezinho, principalmente de alguns nichos abobadados sobre o teto. Em nosso modo de ver, existem indicações claras de uma associação intrínseca entre as unidades e o suporte, sendo na conjunção entre ambos que a mensagem foi criada. É dessa maneira que devemos compreender a construção simbólica desse sítio. Uma conjunção entre unidades gráficas, suporte e a inserção na paisagem, única em toda essa região do município de Pão de Açúcar, delimitada e protegida pela alta vegetação circundante.

\section{Agradecimentos}

À Fundação de Amparo à Pesquisa do Estado de São Paulo (FAPESP), ao Paulo Zanettini e à Zanettini Arqueologia.

GUEDES, C.M. Rock-art research at Sertão Alagoano: the Cosmezinho site (CZ). R. Museu Arq. Etn., 25: 215-230, 2015.

Abstract: In the year of 2008, Zanettini Archeologia in interaction with IPHAN-AL began a process of identifying, recording and evaluating of rock-art sites in the backlands of Alagoas, proposing strategies devoted to monitoring, conservation and to the qualified public use of these cultural resources of the region. This work led to the diagnostic program of the rock-art sites in the city of Pão de Açúcar, assessing their conservation status and proposing ways of qualified use of these sites. In addition to the diagnoses made from the assessments on these sites, the data collected within this program have provided a rich documentation for further research, focusing primarily on systematic recording of sites and rock-art panels. These sites in the backlands of Alagoas bear a striking art, branding and this area with quality, formal and thematic variety, and techniques used in the construction of the panels. The aim of this work is to describe the methods and analyzes performed on the site of non-figurative paintings, the Cosmezinho site.

Keywords: Rock-art - Alagoas - Conservation - non-figurative units 


\section{Referências Bibliográficas}

Álvarez, A.M. 2010. Los signos rupestres del paleolítico: La Cueva de El Castillo (Puente Viesgo, Cantabria). Cantabria. S.l.: Gea Patrimonio.

Baeta, A.M. 1989. Levantamento e Documentação de Grafismos Rupestres no Carste de Lagoa Santa. Belo Horizonte: Setor de Arqueologia MHN/UFMG- FAPEMIG. Relatório (não publicado).

Calderón, V. 1983. Estudos de Arqueologia e Etnologia. Salvador: UFBA.

Cavalheiro, A.C.M. 2004. Pinturas rupestres nos Campos Gerais. Dissertação de mestrado (Arqueologia). São Paulo: Faculdade de Filosofia, Letras e Ciências Humanas, USP.

Consens, M. 1984. La Arqueología como Fundamento de la Utilización de Técnicas y Métodos en los Procesos de Investigación del Arte Rupestre. Revista do CEPA, 12 (14): 13-47.

Consens, M. 1985. Comentarios Acerca de un Enfoque Arqueológico para Investigar en Arte Rupestre. In. Aldunate, C., Berenguer, J. y Castro, V. (Eds). Estudios en Arte Rupestre. Santiago de Chile: Museo Chileno de Arte Precolombino, p. 3-11.

Guedes, C.M. 2014. A semántica dos signos em arte rupestre: Estruturas da Cognição. Tese de doutorado. São Paulo: Museu de Arqueologia e Etnologia, USP.

Hodder, I. 1982. Art, decoration and style. I, Hodder, I. The present past: an introduction to anthropology for archaeologists. London: Batsford, p. 173-195.
Renfrew, C.; Zubrow, E.B. 1994. The ancient mind: elements of cognitive archaeology. Cambridge: Cambridge University Press.

Sauvet, G. 1993a. La composition et l'espace orné. In: Groupe de Refléxion sur l'Art Pariétal Paléolithique - L'art Pariétal Paléolithique. Techniques et méthodes d'études. Paris : Éditions du C.T.H.S., p. 297-309.

Sauvet, G. 1993b. Le problème de la détermination. In: Groupe de Refléxion sur l'Art Pariétal Paléolithique - L'art Pariétal Paléolithique. Techniques et méthodes d'études. Paris : Éditions du C.T.H.S., p. 83-86.

Vialou, D. 1998. Problématique de l'interprétation de l'art paléolithique. Rivista di Scienze Preishiriche, XLIX, p. 267-281.

Vialou, D. 1999. L'art paléolithique. In: Otte, M. La Prehistoire. Paris/Bruxelles: DeBoeck Université, p. 213-289.

Vialou, D. 2009. L'image du sens, en préhistoire. In : L'Anthropologie 113. Pp. 464-477.

Zanettini Arqueologia. 2007. Programa de Diagnóstico e Ações Emergenciais em Sítios Rupestres, municípios de Olho D'Água do Casado e Delmiro Gouveia, Alagoas. Relatório Final apresentado à 17a Superintendência Regional do IPHAN (não publicado).

Zanettini Arqueologia. 2009. Programa de mapeamento, cadastro e conservação dos sítios de arte rupestre do Baixo São Francisco - Etapa 1. Pão-de-Açúcar. Relatório Final apresentado á $17^{\mathrm{a}}$ superintendência Regional do IPHAN (não publicado). 